\title{
Structure and Dynamics of Humpback Whales Competitive Groups in Ecuador
}

\author{
Fernando Félix $^{1}$ and Johana Novillo ${ }^{2}$ \\ ${ }^{1}$ Museo de Ballenas. Av. General Enríquez Gallo, between 47 \& 50 St. Salinas, Ecuador \\ ${ }^{2}$ Av. El Inca y Francisco de Izazaga, Quito, Ecuador \\ *Corresponding author (Email: fefelix90@ hotmail.com)
}

Citation - Félix, F., \& Novillo, J. (2015). Structure and dynamics of humpback whales competitive groups in Ecuador. Animal Behavior and Cognition, 2(1), 56-70. doi: 10.12966/abc.02.05.2015

\begin{abstract}
We assessed the social structure and behavior of humpback whale (Megaptera novaeangliae) competitive groups off Ecuador between July and August 2010. During this time we followed 185 whales in 22 competitive groups for $41.45 \mathrm{hr}$. The average group size was 8.4 animals $(S D=2.85)$. The average sighting time was $113.05 \mathrm{~min} /$ group $(S D=47.1$ ). We used photographs of dorsal fins and video to record interactions and estimate an association index (AI) between each pair of whales within the groups. Sightings were divided into periods, which were defined by changes in group membership. On average, group composition changed every 30.2 min, which confirms that the structure of competitive groups is highly dynamic. Interactions between escorts characterized by low level of aggression. At least $60 \%$ of escorts joined or left together the group in small subunits between two and five animals, suggesting some type of cooperative association. Although singletons, as well as pairs or trios were able to join competitive groups at any moment, escorts that joined together were able to stay longer with the group and displace dominant escorts. Genetic analysis showed that in three occasions more than one female was present within a competitive group, suggesting either males are herding females or large competitive groups are formed by subunits. Males and females performed similar surface displays. We propose that competition and cooperation are interrelated in humpback whales' competitive groups and that male cooperation would be an adaptive strategy either to displace dominant escorts or to fend off challengers.
\end{abstract}

Keywords - Behavior, Competitive groups, Cooperation, Humpback whales, Megaptera novaeangliae

The Southeast Pacific humpback whale (Megaptera novaeangliae) population, also referred as to Breeding Stock G, is one of seven Antarctic stocks recognized by the International Whaling Commission (IWC, 1998). This population breeds during the austral winter and spring (June-October) along the northwest coast of South America (northern Peru, Ecuador and Colombia) and southwest Central America (Panama and Costa Rica), and feed during summer months along southern Chile and western Antarctic Peninsula (Acevedo et al., 2007; Félix \& Haase, 2001; Flórez-González et al., 2007; Rasmussen et al., 2007). The species has been studied continuously for over 20 years off the coast of Ecuador to address population, ecological and conservation issues (Félix \& Botero, 2011; Félix \& Haase 2001; Félix, Muñoz, Falconí, Botero, \& Haase, 2011).

The reproductive behavior of humpback whales has been studied in tropical areas where the species concentrates around oceanic islands such as Hawaii (Baker \& Herman, 1984; Darlin et al., 2006) the Caribbean (Clapham, Palsboll, Matilla, \& Vasquez, 1992; Tyack \& Whitehead, 1983) and mainland east Australia (Brown \& Corkeron, 1995), among others. The term competitive group was proposed by Clapham et al. (1992) to refer to some groups found at breeding grounds and characterized by a dynamic structure and intense competition among males supposedly to access receptive females. Competitive groups have been observed in all breeding areas and occasionally in feeding grounds (Weinrich, 1995). 
These groups were initially described as hierarchically structured, formed by a passive nuclear animal (the female), a principal escort (male) who maintained a privileged position next to the female, and several secondary escorts (males) who challenge the principal escort (Baker \& Herman, 1984; Tyack \& Whitehead, 1983). Males would engage in agonistic fights trying to gain the dominant position which they defended aggressively. Behavioral displays associated with these groups include threatening postures such as head lunges and underwater exhalation as well as more aggressive displays including direct physical contact with charges and peduncle/tail strikes.

A less structured array was described by Clapham et al. (1992), who were not able to identify a principal escort in all competitive groups they studied in the Caribbean, and suggested that some males would form coalitions to displace dominant animals. Brown and Corkeron (1995) reported that most interactions between males in competitive groups in migrating humpback whales off eastern Australia were non-agonistic and occasionally cooperative. Similar type of interactions were reported in Hawaii by Darling, Jones and Nicklin (2006), who refer to the songs as a mechanism for mediating interactions between males, including potential cooperation behavior in competitive groups. Félix (2004) also referred to competitive groups as a type of cooperative association between males for accessing receptive females, and described specific energetic displays that would help to organize males at forming competitive group in Ecuador. Pomilla and Rosenbaum (2006) found that if cooperative behavior is present in breeding humpback whales off Gabon and Madagascar, it is not favored by related animals.

Based on studies of competitive groups, it was suggested that the reproductive system of humpback whales is some variant of polygyny (Baker \& Herman, 1984; Brown \& Corkeron, 1995; Clapham, 1996). The breeding behavior of humpback whales has been compared to the lek-breeding system of some ungulates (Baker \& Herman, 1984; Clapham, 1996), but unlike the classical lek, humpback whale males do not establish territories neither monopolize females. Because male humpback whales could establish dominance under a temporary-residence basis, Clapham et al. (1992) called it "floating lek", as some of the characteristics associated with the lek such as a male display (e.g., singing, breaching) and competition between males for the access to receptive females from other rival males do occur. However, it is unknown to what extent dominant males can in fact defend their position and eventually copulate with several females in an extensive and homogeneous breeding area, where territories would necessarily be very temporary. The high proportion of non-agonistic male interactions and some evidence of cooperation behavior would suggest dominance by sexual coercion (Darling et al., 2006), which may led to females sometimes behave aggressively in competitive groups (Clapham et al., 1992).

Despite having a licentious reproductive system, it is expected that both males and females should maximize reproductive benefits while minimizing energy expenditure (e.g., Craig, Herman, \& Pack, 2002; Pack et al., 2009, 2012). It has been suggested that by accompanying a female, males practice mate guarding behavior, prior or post copulation, to prevent copulation from other males (Clapham, 1996; Mobley \& Herman 1985). Encouraging competition would be a mechanism used by females to select best mates (Darling, 2001). The use of molecular techniques has shown that the social dynamics within competitive groups are complex and not necessary all of them contained a female (Brown \& Corkeron, 1995; Clapham et al., 1992); all male groups may account up to a third of these groups (Clapham et al., 1992). In others cases two or more females are present in the same competitive group (Pomilla \& Rosenbaum, 2006).

Notwithstanding these advances in the reproductive behavior of the species, there is still uncertainty about the purpose of competitive groups and the specific role of each individual, as copulation has not seen in humpback whales. In this paper we compare the structure and social behavior of competitive groups in Ecuador with those reported elsewhere. We are aware that assessing the social behavior in highly mobile animals that spend long time below the surface is puzzling, particularly in identifying complex social hierarchical interactions that characterize competitive groups such as dominance, cooperation or male-male challenges. 


\section{The Study Area}

\section{Method}

The study was conducted around the Santa Elena Peninsula at Salinas, south-central coast of Ecuador $\left(2^{\circ} 10^{\prime} \mathrm{S} 81^{\circ} 00^{\prime} \mathrm{W}\right)$ (Figure 1). The Peninsula is surrounded by a narrow shelf where depth increases gradually from the Peninsula tip to the west; reaching $100 \mathrm{~m}$ in depth $13 \mathrm{~km}$ offshore. The area is located in the southern part of the Southeast Pacific humpback whales breeding grounds, which extends around 3,000 $\mathrm{km}$ from the north of Peru $\left(5-6^{\circ} \mathrm{S}\right)$ to the South of Costa Rica $\left(10^{\circ} \mathrm{N}\right)$ (Flórez-González et al., 2007; Pacheco, Silva, \& Alcorta, 2009; Rasmussen et al., 2007).

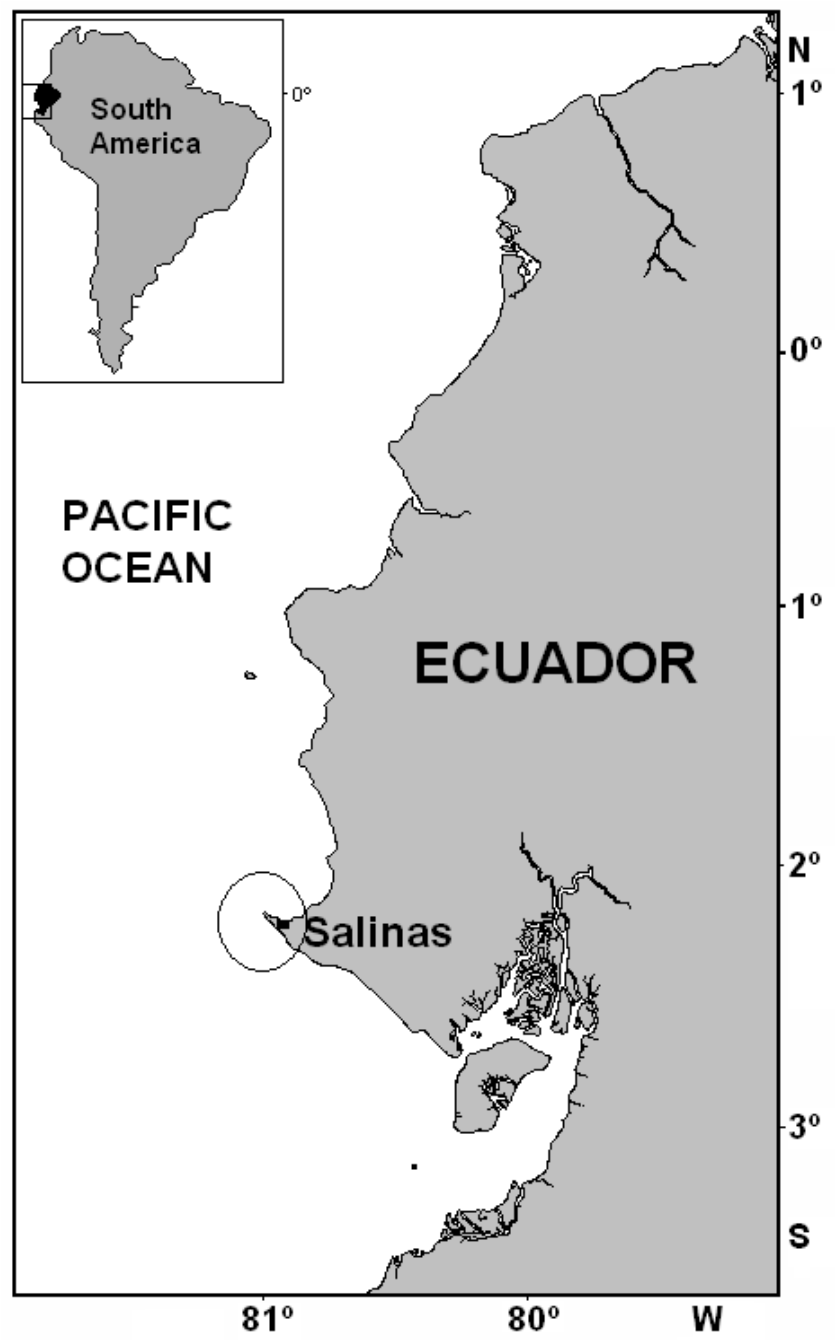

Figure 1. The study area in Ecuador.

\section{Surveys and Data Collected}

We conducted 20 surveys between July $26^{\text {th }}$ and August $30^{\text {th }}$, 2010, to assess the social structure and behavior of competitive groups. For this purpose we used a $9 \mathrm{~m}$ length open boat with a $75 \mathrm{HP}$ outboard engine. Groups were approached to a distance that allowed taking photographs of whales with a minimum disturbance $(30-50 \mathrm{~m})$. Whales were followed until the group split, were lost or until fuel allowed it.

The team included three researchers, one skipper and one crew. Tasks on board included photography, video, skin sampling and data record. Digital cameras equipped with 70-300 mm zoom lens 
and 12-18 megapixels and a digital video camera (Samsung SC-D372, 34X Optical Zoom) were used to identify individuals and record behavior. Dorsal fin shapes, visible scars and wounds around this area were used for individual identification, a technique used in similar studies (e.g., Baker \& Herman, 1984; Clapham et al., 1992). Photographs and video of whales' back were taken when breathing to determine group composition based on recognizable individuals. Photographs were processed the same day once in port. Each individual in the group was assigned a number based on own characteristics. The permanence of an individual within the group was estimated using the time of the first and last digital photographs taken of that individual.

Data collected included position, time of day, number of animals, surface activity (number and type of energetic displays on surface) and general behavior. Five energetic displays recorded included backward breaching, forward breaching, tail slapping, flipper slapping and tail lashing. Such information was collected every $15 \mathrm{~min}$ and used to estimate an average group activity rate (GAR) along the observation period.

\section{Definitions}

Surface activity: refers to those deliberate actions exhibited by whales other than swimming and breathing, specifically displays that implicated striking the water surface with appendages or any other part of the body (see Félix \& Botero, 2012).

Competitive Group: refers to an intricate and dynamic association formed by humpback whales during the breeding season, characterized by fast swimming with continuous changes of heading and with some moments of energetic surface displays (e.g., Baker \& Herman, 1984; Clapham et al., 1992; Tyack \& Whitehead, 1983). The term is equivalent to surface active groups used by Darling et al. (2006). Animals were considered as part of a competitive group if they were within $100 \mathrm{~m}$ of each other, swimming with a synchronized breathing/diving pattern, and seemed to be a unit.

Nuclear animal: the individual who usually is in the middle or in front of a competitive group, which apparently is the focus of other whales referred as to escorts (see Tyack \& Whitehead, 1983).

Escort: all whales not identified as the nuclear animal.

Initial escort: escort identified as such when the groups was first time approached.

Subgroup/subunit: whales that joined or left the group together in pairs or larger.

Sighting time: total time that a group was followed.

Period: unit in which the sighting time was divided to indicate changes in membership occurred either by affiliation, disaffiliation or both.

Age/class: we distinguished three different age/class categories in the whales based on their relative size by eye: adults, subadult and calves. The last class in a close association with an adult, who was assumed to be the mother.

Group type: based on the type of individuals present, we identified four different competitive groups: $\mathrm{A}=$ all adult animals, $\mathrm{AS}=$ adults with at least one subadult, $\mathrm{MC}+n \mathrm{E}=$ mother with calf plus $n$ escorts. 


\section{Association Index (AI)}

To assess the degree of relationship between participants in a competitive group an association index was calculated as following:

$A_{b}=T_{t} /\left(T_{a}+T_{b}-T_{t}\right)$

where,

$\mathrm{A}_{\mathrm{b}}=$ Index of association between a pair of individuals " $a$ " and " $\mathrm{b}$ " in the group;

$\mathrm{T}_{\mathrm{t}}=$ Time that individuals "a" and " $\mathrm{b}$ " were recorded together;

$\mathrm{T}_{\mathrm{a}}=$ Total time that individual " $\mathrm{a}$ " was recorded;

$\mathrm{T}_{\mathrm{b}}=$ Total time that individual " $\mathrm{b}$ " was recorded.

The computation of this index is a number between 0 and 1 . Zero indicates that two individuals were seen in the same group but in different periods, and 1 means that two individuals were seen together during the time they formed part of the group. We are aware that an AI $=1$ does not necessarily imply that two animals were in close proximity during the sighting; it may be the case that an animal maintained in the periphery of the group. Association indexes within the groups were averaged and used in different statistical analysis.

\section{Sampling and Molecular Analyses}

Sloughed skin samples were collected opportunistically after whales made an energetic aerial display as described in Félix and Botero (2012). Samples were stored in 95\% ethanol and then at refrigerated temperature (around $4{ }^{\circ} \mathrm{C}$ ) prior to laboratory analysis. A fragment of approximate length 500 bp of the mtDNA control region (CR) was amplified via the Polymerase Chain Reaction using standard reaction conditions and protocols used in previous studies with this species (see Félix, Caballero, \& Olavarría, 2012; Olavarría et al., 2007). We tried to obtain as many samples as possible from a group. When more than one sample was taken from the same group, resampling was assumed if the sex and mtDNA of the samples matched. Sex specific markers for gender determination followed the methodology of Gilson, Sylvanen, Levine, and Banks (1998), which amplify a 224 bp fragment of the $S R Y$ gene located on the Y chromosome. As internal positive control against PCR amplification failure, the homologous ZFY/ZFX region (445 bp) was also amplified.

\section{Results}

\section{Groups and Effort}

Twenty-two competitive groups were evaluated during this study. The total sighting time was 2,487 $\mathrm{min}(41.45 \mathrm{hr})$. The average sighting time was $113.05 \mathrm{~min}$ per group $(S D=47.1$, range 46-209 $\mathrm{min})$. The total number of animals observed was 185 . The average number of whales recorded during the sighting period was 8.4 animals $(S D=2.85$, range 3-17). According to age/class composition there were 12 all-adults groups (A), 8 adults and subadults (AS), one involved a mother/calf pair and eight escorts $(\mathrm{MC}+8)$, and one undetermined (Table 1). 
Félix and Novillo 61

Table 1

Information on sighting effort, group size and composition, surface activity, group dynamics and sex recorded in 22 competitive groups assessed off Ecuador. Surface displays include $B B=$ backward breaching, $F B=$ forward breaching, $T S=$ tail slapping, $F S=$ flipper slapping, and $T L=$ tail lashing

\begin{tabular}{|c|c|c|c|c|c|c|c|c|c|c|c|c|c|c|c|c|c|c|}
\hline \multirow{3}{*}{$\begin{array}{l}\text { Group } \\
\text { ID }\end{array}$} & \multicolumn{4}{|c|}{ General information } & & \multicolumn{5}{|c|}{ Surface activity } & \multicolumn{7}{|c|}{ Group dynamics } & \multirow[t]{2}{*}{ Genetics* } \\
\hline & & Sighting & & & & & & & & & \multicolumn{3}{|c|}{ Affiliation (\#) } & \multirow{2}{*}{$\begin{array}{l}\text { Disaffiliation } \\
\text { (\#) }\end{array}$} & \multicolumn{2}{|c|}{ Displacement (\#) } & \multirow{3}{*}{$\begin{array}{l}\text { Maintain } \\
\text { Position } \\
\text { pair }\end{array}$} & \\
\hline & $\begin{array}{l}\text { Whales } \\
\text { /group }\end{array}$ & $\begin{array}{l}\text { time } \\
(\min )\end{array}$ & $\begin{array}{l}\text { Group } \\
\text { Type }\end{array}$ & $\begin{array}{l}\text { Avg. } \\
\text { AI }\end{array}$ & Periods & BB & FB & TS & FS & $\mathrm{TL}$ & Short & Mid & Join & & Partial & Total & & Sex and sampled displays \\
\hline 1 & 5 & 46 & A & 0.91 & 2 & 1 & & & & & & & & 1 & & & & $1 \mathrm{M}(\mathrm{BB})$ \\
\hline 2 & 10 & 153 & $\mathrm{MC}+8$ & 0.43 & 4 & & 3 & & & & 1 & 1 & & 1 & & 1 & none & \\
\hline 3 & 4 & 185 & A & 0.46 & 3 & 8 & 2 & 22 & 21 & 12 & & & & & & 1 & none & $2 \mathrm{M}(\mathrm{BB})$ \\
\hline 4 & 12 & 168 & AS & 0.44 & 5 & 44 & 3 & & 25 & & & 3 & 2 & 1 & & & trio & $2 \mathrm{~F}, 1 \mathrm{M}(\mathrm{BB})$ \\
\hline 5 & 9 & 209 & AS & 0.3 & 5 & 48 & 12 & 1 & 70 & 10 & 1 & 1 & 1 & 2 & & & single & $3 \mathrm{~F}(1 \mathrm{TL} \& 2 \mathrm{BB}), 1 \mathrm{M}(\mathrm{BB})$ \\
\hline 6 & 6 & 49 & A & 0.72 & 2 & 1 & & & & & & 1 & & & & & single & \\
\hline 7 & 11 & 71 & A & 0.47 & 3 & 15 & 2 & 3 & 12 & 1 & & 1 & & & & 1 & none & $1 \mathrm{M}(\mathrm{BB})$ \\
\hline 8 & 10 & 79 & A & 0.42 & 3 & 3 & & & & & 2 & & & 2 & & & single & \\
\hline 9 & 5 & 171 & AS & 0.57 & 6 & 107 & 58 & 1 & & 17 & 1 & & 1 & & & & pair & $2 \mathrm{M}(\mathrm{TL} \& \mathrm{BB})$ \\
\hline 10 & 9 & 113 & A & 0.76 & 3 & 16 & 10 & & 5 & 6 & & & 1 & 1 & & & quad & $1 \mathrm{M}, 1 \mathrm{~F}(\mathrm{BB})$ \\
\hline 11 & 10 & 128 & $\mathrm{U}$ & 0.48 & 3 & 23 & 2 & 2 & 14 & 17 & 1 & & 1 & 2 & & & pair & $1 \mathrm{~F}(\mathrm{BB})$ \\
\hline 12 & 7 & 118 & AS & 0.35 & 4 & & & 1 & 13 & 1 & 1 & 1 & & & 1 & & single & \\
\hline 13 & 7 & 128 & AS & 0.44 & 4 & 4 & 3 & 6 & 13 & 17 & & 2 & & & 1 & & single & $2 \mathrm{~F}(\mathrm{TL} \& \mathrm{BB})$ \\
\hline 14 & 17 & 85 & AS & 0.34 & 4 & & & & 30 & & 1 & 3 & 1 & 2 & & & single & \\
\hline 15 & 8 & 105 & A & 0.41 & 4 & 3 & & & & 15 & 1 & 1 & & & & 1 & single & $1 \mathrm{M}(\mathrm{TL})$ \\
\hline 16 & 10 & 77 & A & 0.6 & 4 & & & & & & 1 & & 1 & 1 & & & quad & \\
\hline 17 & 8 & 156 & AS & 0.57 & 4 & & & 1 & 1 & 1 & & 2 & 1 & & & & trio & \\
\hline 18 & 9 & 106 & AS & 0.42 & 4 & 4 & 1 & 1 & 12 & 4 & 1 & & & 2 & & & single & $2 \mathrm{M}(\mathrm{TL} \& \mathrm{BB})$ \\
\hline 19 & 5 & 146 & A & 0.45 & 4 & 3 & & & 27 & 2 & 1 & & & & & & pair & $1 \mathrm{~F}(\mathrm{BB})$ \\
\hline 20 & 8 & 62 & A & 0.67 & 3 & & & & & & & 1 & & 2 & & & trio & \\
\hline 21 & 8 & 62 & A & 0.83 & 3 & 1 & & & & 1 & & & & 2 & & & single & $1 \mathrm{M}(\mathrm{BB})$ \\
\hline 22 & 7 & 70 & A & 0.68 & 3 & & & & & & & 1 & & 1 & & & single & \\
\hline TOTAL & 185 & 2487 & & & 80 & 281 & 96 & 38 & 243 & 104 & 12 & 18 & 9 & 20 & 2 & 4 & & 23 \\
\hline
\end{tabular}

*Includes the description to the surface display performed by a whale when slugged skin was sampled. 


\section{Association Index and Affinity with the Nuclear Animal}

The level of association between individuals was highly variable among groups (Figure 2). The overall AI was $0.47(S D=0.38)$. A significant but moderate negative correlation was found between sighting time and the average $\mathrm{AI}(r=-0.56, d f=20, p<0.01)$. In all groups there were animals with the maximum affinity $(\mathrm{IA}=1)$. We distinguish two types of associations with $\mathrm{AI}=1$ : a) those formed by escorts associated during the entire observation period with the nuclear animal, which including 10 singles and 9 small subunits between two and four animals, and b) small subunits of up to five escorts that entered or left the group together during the observation period $(n=29)$ (Figure 3). There were 99 escorts involved in these 38 associations or subunits, which is equivalent to $53.5 \%$ of the total recorded animals. Considering that at least one female would be present in each group (but see Table 1), at least $60.7 \%$ of escorts participated in this type of associations.

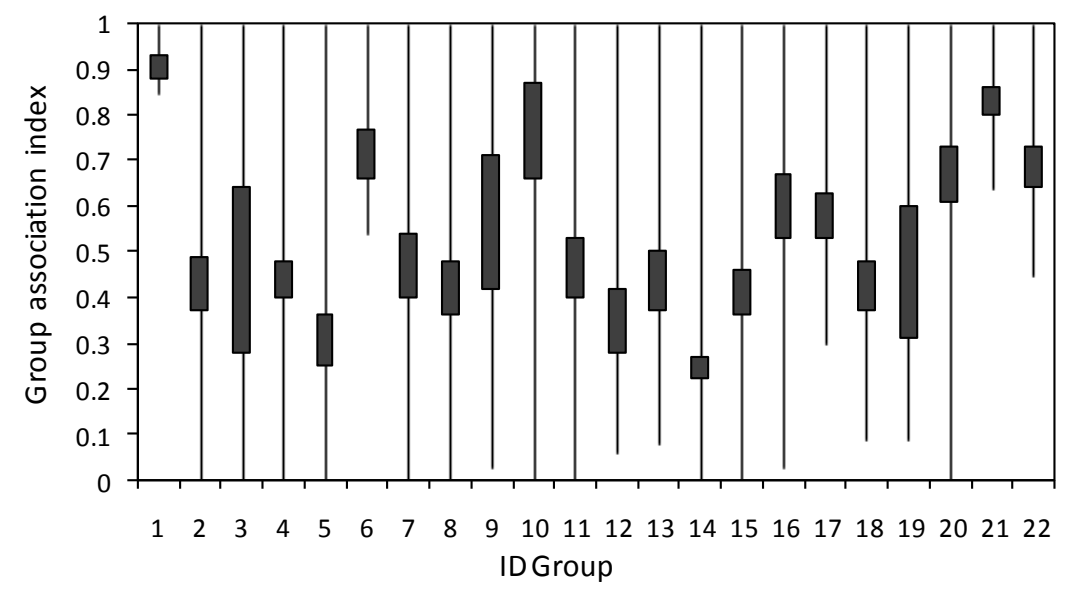

Figure 2. Average group association index (AI). The figure shows the AI average value, \pm the standard error (dark square blocks), and the maximum and minimum values in the 22 competitive groups evaluated.

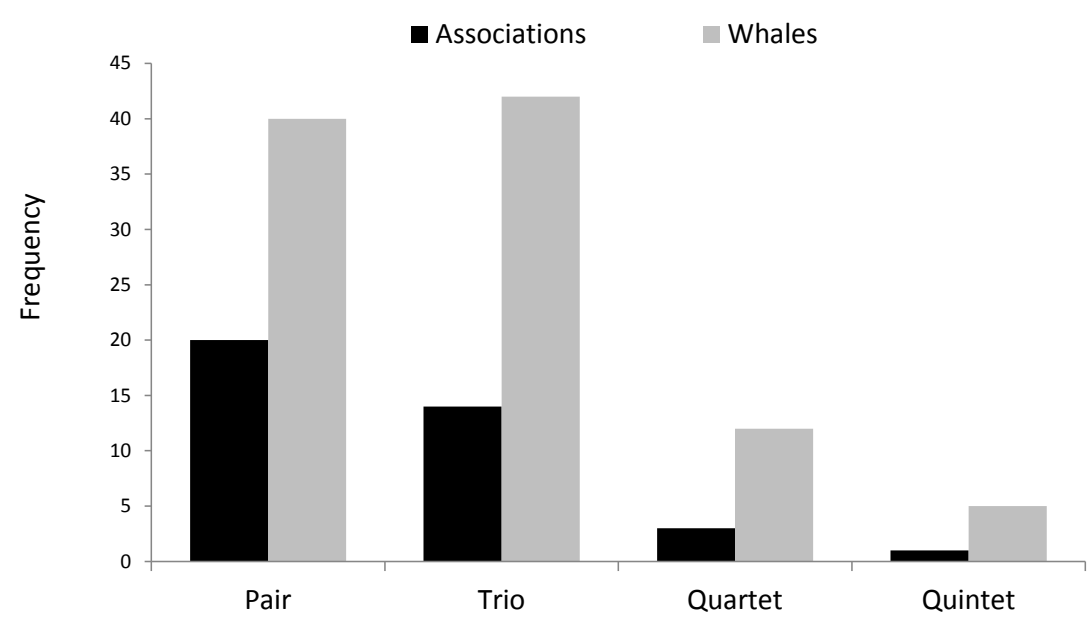

Figure 3. Number and type of group associations of escorts with $\mathrm{AI}=1(n=38)$. The total number of animals that participated in these subunits was 99.

\section{Dynamics of Competitive Groups}

Sixty-five changes in membership were recorded, involving 111 animals (Tables 1 and 2). Changes occurred on the average every $30.2 \mathrm{~min}(S D=21.33)$. There were 3.6 periods of change per 
group on the average ( $S D=0.95$, range 2-6) (Figure 4). As expected, a strong positive and highly significant correlation between the observation time and the number of periods per group was found $(r=$ $0.73, d f=20, p<0.01)$. The average changes in membership per group was $7.86(S D=5.08$, range $1-10)$. Correlation between group size and number of period or sighting time were not significant $(r=0.32$ and $r$ $=-0.07, p>0.05$ in both cases). These results suggest that competitive groups form opportunistically and the association time is highly variable and unrelated to group size.

Table 2

Changes in membership occurred in the 22 competing groups. Six different situations are described and its frequency of occurrence quantified according to group size

\begin{tabular}{lccccc}
\hline & Single & Pair & Trio & Quartet & Quintet \\
\hline Initial escorts left the group & 11 & 5 & 2 & 1 & 1 \\
Initial escorts substituted & 3 & 2 & & & \\
Initial escorts partially substituted & 1 & & & & \\
Escort joined the group & 6 & 1 & 2 & & \\
Escort affiliated temporally & 9 & 3 & 6 & & \\
Escort affiliated briefly & 7 & 3 & 1 & 1 & \\
Total subgroups & & 14 & 11 & 2 & 1 \\
Total individuals & 37 & 28 & 33 & 8 & 5 \\
\hline
\end{tabular}

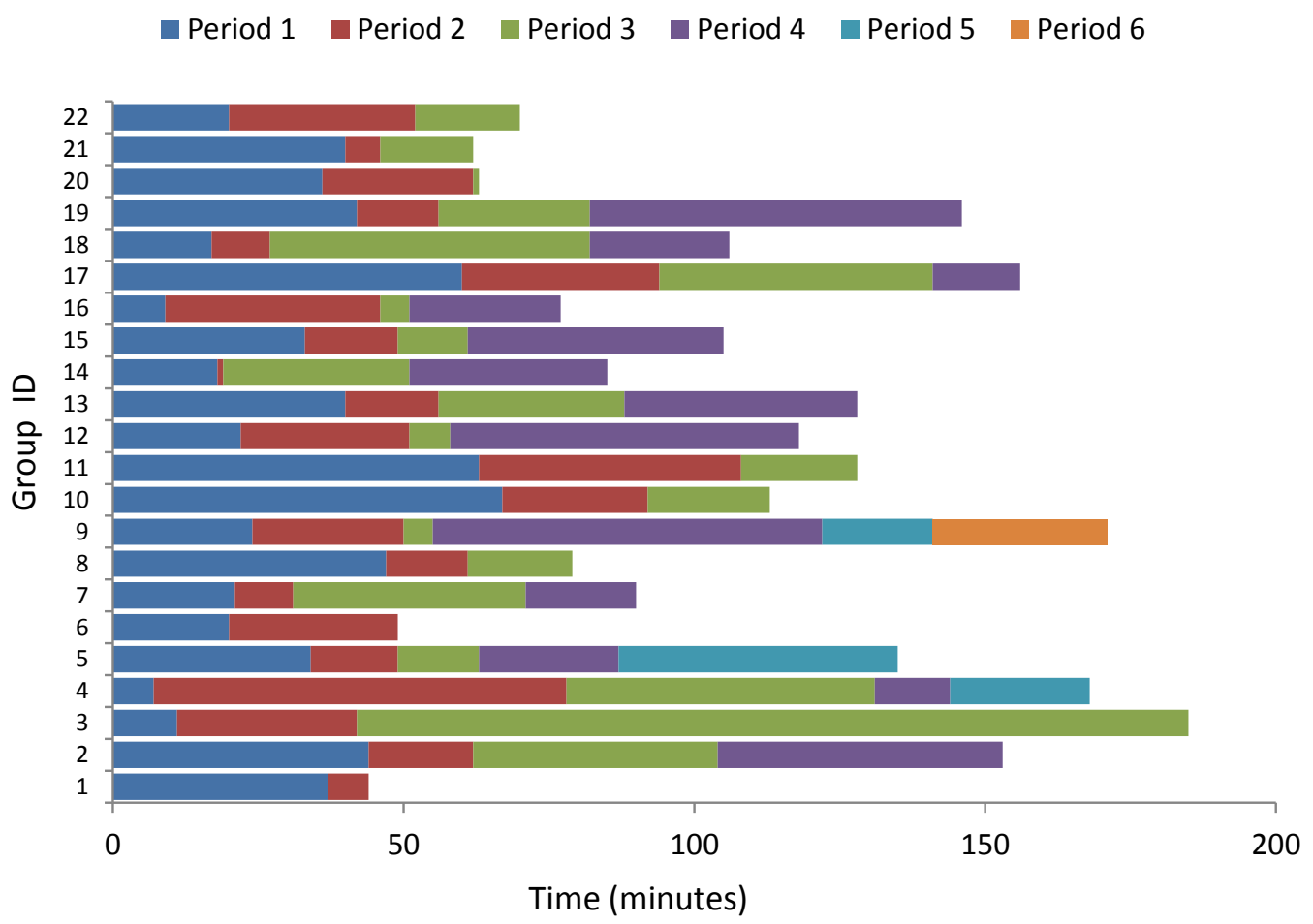

Figure 4. Number of periods recorded in the 22 competitive groups assessed. Each color corresponds to a period where changes in membership occurred. 
Six different contexts related to affiliation, disaffiliation and displacement of escorts were evaluated (Table 2). Table 3 describes in detail the number of individuals involved in these changes. The following is a summary of the most relevant interactions:

1) Changes in group structure involving single individuals occurred in 37 cases (57\% of the total changes recorded) which represented $33.3 \%$ of total animals. The remaining whales affiliated or disaffiliated as pairs, trios, quads and quintets.

2) Initial escorts disaffiliated as singles (11 cases) or subgroups (9 cases as pairs or larger involving 25 animals) at different times for unknown reasons. It is presumed that those cases would correspond to challenges who failed their attempt to improve position or were part of a group that split for other reason.

3) In 6 competitive groups initial escorts were displaced by other escorts. In all cases successful challengers were part of a subgroup instead of challenging the main escort by themselves. In four cases, all initial escorts, three singles and a pair were replaced by three trios and a quad. In two cases only one of the initial escorts was replaced (1 single and a pair) by a pair and a trio. The subgroups which replaced the initial escorts formed stable associations during the rest of the observation period; only 3 of 17 individuals (18\%) disaffiliated before the group was left.

4) In 9 cases (23\%) escorts joined the group for the remainder observation period; this included 6 singletons and 8 individuals in pairs and trios. The rest joined but disaffiliated before the sighting ended.

5) Most of the escorts who affiliated temporarily (> $20 \mathrm{~min})$ involved subgroups: trios $(n=18$, $55 \%)$, pairs $(n=6,18 \%)$ and singletons $(n=9,27 \%)$.

6) Most brief affiliations (<20 min) involved singletons (58\%) or pairs $(25 \%)$.

The events described above indicate that only pairs and trios were successful in replacing dominant escorts. Although singletons were able to join competitive groups, their association time with the group was shorter than in the case of pairs and trios.

In four cases the observation finalized when the group split and we remained with two whales (Groups \#6, 14, 18, 21 and 22). In Group 6 the split pair contained the initial escort and the identified nuclear animal. Three of those (Groups \#6, 14 and 22) finalized when trios joined, which could be a destabilization factor that sets up the conditions to reorganize the group. In all but one case the remaining whales continue with the active behavior typical of a competitive group moving away.

Table 3

\begin{tabular}{|c|c|c|}
\hline Group Class & Cases & Whales \\
\hline None & 3 & \\
\hline One & 10 & 10 \\
\hline Two & 4 & 8 \\
\hline Three & 3 & 9 \\
\hline Four & 2 & 8 \\
\hline TOTAL & 22 & 35 \\
\hline
\end{tabular}

\section{Surface Activity}

The number of energetic displays recorded in each group is shown in Table 1 . There were eight groups in which the five displays assessed were recorded (3 A groups, 3 AS groups and 1 unknown). In all AS groups at least one display was recorded. On the other hand, there were three A groups in which none display was recorded. In general, AS groups had the highest surface activity in all five displays assessed. Displays more often recorded were backward breaching $(n=281)$ and flipper slapping $(n=$ 
243). This last display probably was underestimated because not always was possible to record all executions particularly if were performed repeatedly by more than one animal.

Displays were not performed with the same intensity along the sighting but in short bursts. The estimated average group activity rate (GAR) showed values between 0.9 to 7.8 displays/15 min of sighting (Figure 5). There were two peaks of maximum activity; in the first 15 min after the groups were approached and then during the period 75-90 min. After this, the activity decreased until minute 180, but this may be biased downward because a lower number of groups were used to compute GARs after minute 120. Peaks of activity would be related with periods of challenges or displacement of escorts. The average time at which pairs or trios of escorts that displaced initial escorts joined the group was minute 62 ( $n=6$ cases, Table 1$)$, this is previous the period with maximum surface activity. Three of those groups showed high level of surface activity (Groups \#3, 7 and 13), two moderate activity (Groups \#12 and 15) and one low activity (Group \#2) (Table 1).

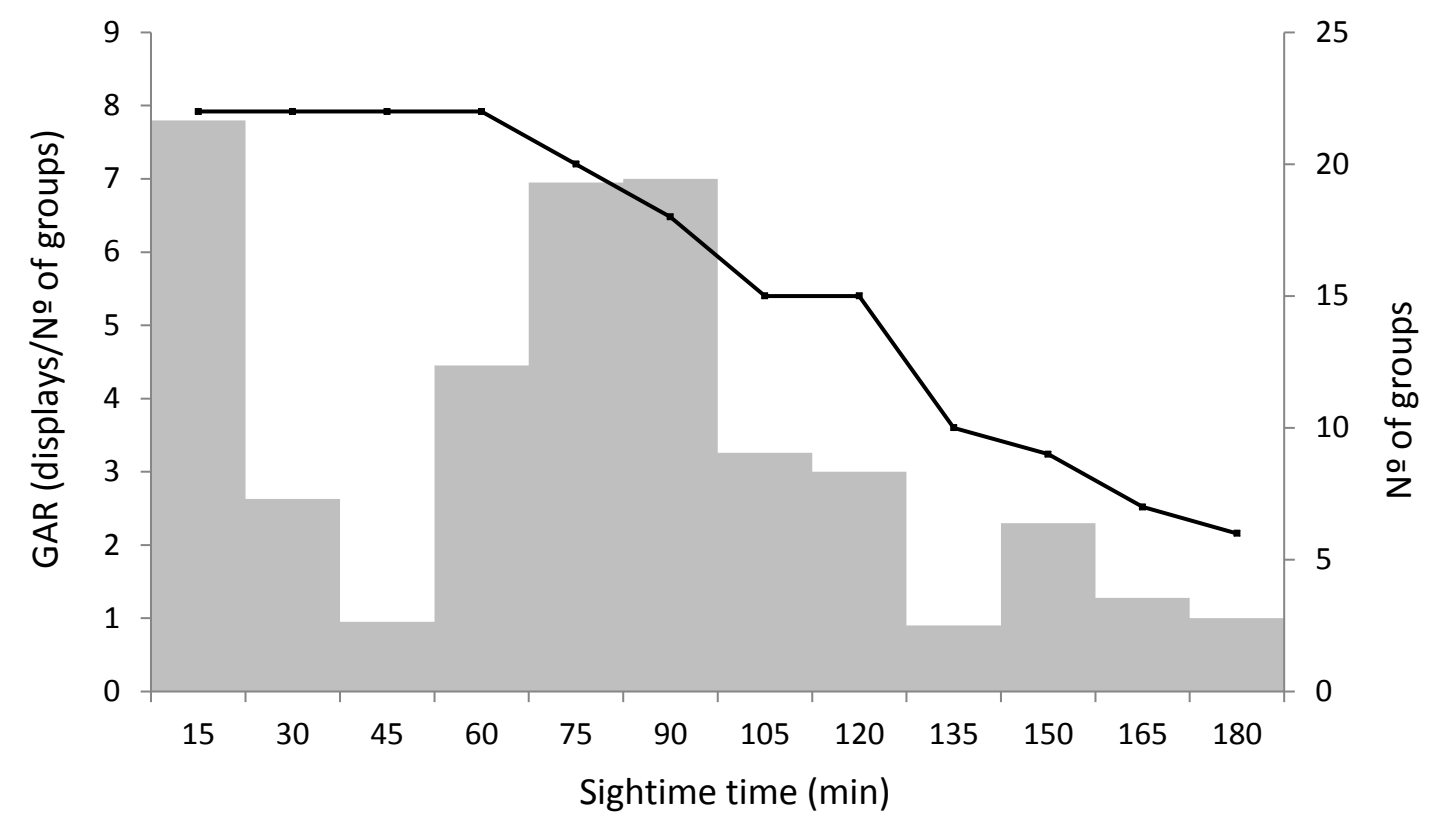

Figure 5. Average group activity rate (GAR) (displays/\# of groups) performed by whales in competitive groups in Ecuador during the first three hours of following. Line with dots indicates the number of groups used to calculate GAR according the scale of the right axis.

\section{Sex Composition}

Excluding duplications, twenty-three different animals were sexed in 13 groups: 13 males and 10 females (Table 1). Mitochondrial analysis revealed that two groups (\#4 and 13) included two females, and one group (\#5) contained three females. In Group \#4 both females were sampled in the second period, one of them was a subadult who maintained mostly in the periphery of the group executing breaches and other surface displays. Eight different animals joined this group including two trios in different periods. This observation lasted $168 \mathrm{~min}$, broken into five sighting periods, and the group size was 12. In Group \#5 the three females were sampled in different periods (1, 3 and 6) at 10:04, 10:48 and 12:43. Four different animals joined this group during the sighting time $(209 \mathrm{~min})$. There were six sighting periods, and the average group size was nine. In Group \#13, the first female was sampled at 12:02 in the first period and the second one at 12:47 in the third period. In the second period a trio joined the group. This observation lasted $128 \mathrm{~min}$, there were four periods, and the group size was nine.

Displays from which skin samples were obtained included 18 backward breaches (10 males and 8 females) and five tail lashes (3 males and 2 females) (Table 1), which indicate that males and females perform these type of displays in similar proportion. 


\section{Formation of Competitive Groups}

Observations of Groups \#2 and 7 started before the actual formation of a competitive group, when following two animals that showed intense surface activity. In both cases one of the initial active animals was displaced by a pair and a trio respectively. In observing No.2 one of the initial active animal was sexed and resulted male (see Table 1). Forty-two minutes later two whales displaced this animal and began to chase the other whale which was later identified as the nuclear animal. One of the new escorts was sexed after a breach and was also a male. Part of the observed action included the chasing, fast swimming, maintaining the nuclear animal in the middle and in several occasions cutting its path. The group continued in the same activity at least 143 min until we left. Observation of Group \#7 also started with two whales showing surface displays such as tail and flipper slapping, tail slashing and breaching. Twenty one minutes later three whales approached fast and behaved aggressively. There were moments of agitation, milling and fast turns, after which the initial escort was displaced, causing a period of chasing. This group was followed for $90 \mathrm{~min}$.

\section{Discussion}

Dynamics of competitive groups formed by humpback whales in Ecuador is similar to what has been observed in other breeding grounds. However, we noted some differences respect to the traditional description of a highly hierarchal group (e.g., Baker \& Herman, 1984; Tyack \& Whitehead, 1983); since our observations agree with more recent descriptions that include lower levels of aggression and sometimes cooperating (e.g., Brown \& Corkeron, 1995; Clapham et al., 1992; Darling et al., 2006; Félix, 2004; Pomilla \& Rosembaum, 2006).

Although we recorded behavioral displays previously described as aggressive such as tail lashing, it was not observed in conjunction with other physical contact behaviors other than rubbing. Some animals even show wounds and scars on the dorsal fins and tubercles on the head probably caused by abrasion. In that sense, competitive groups in Ecuador show similar level of aggressiveness to those migrating humpback whales from the eastern Australia (Brown \& Corkeron, 1995). The difference in levels of aggression could reflect the variability in reproductive strategies from remote populations living in different environments (e.g., oceanic archipelago vs. mainland). However, recent studies in Hawaii show that non-agonistic male-male interactions are by far more common than agonistic ones (Darling et al., 2006), which suggest that the visibility of aggressive displays could cause overestimation of the frequency of such aggressive behavior in earlier studies. Our findings indicate that males and females executed with similar frequency backward breaches and tail lashes within competitive groups. Therefore, it could be the case that during periods of intense surface activity male-male competence and female rejecting male approaches could be occurring. This leaded to Félix and Botero (2012) advising caution when assigning the sex of whales performing energetic surface displays.

Our analysis shows that competitive groups in Ecuador have a dynamic and fluid structure formed by a nuclear animal and escort whales who try to maintain a close association with it. There seems to be no pattern in terms of group membership, number of participants or association time. Sometimes escorts acted individually, while in other cases they seemed to cooperate with other whales. It is possible that the strategy to be used depends on social factors that could not be evaluated such as physical maturity of the participants, reproductive status of the female and kinship (but see Pomilla \& Rosenbaum, 2006), among others. Most temporary affiliations, in which no obvious aggression was seen could be the result of prospecting males rather than challenging dominant ones, perhaps assessing the "quality" of the female in question before expending energy in a true competition (see Pack et al., 2012). In some cases, single individuals, or subgroups, joined a competitive group permanently without an obvious substitution of escorts, suggesting some flexibility in the structure of the groups. We recorded only six occasions of displacement of initial escorts, likely because of the relative short sighting time. Tyack and Whitehead (1983) reported that the displacement of the main escorts in the Caribbean came on the average after 7.5 hours. 
The entry and departure of animals together in Caribbean competitive groups ( $n=8$ cases) was interpreted by Clapham et al. (1992) as evidence of cooperation between males. Our results support this conclusion as we observed similar behavior in 38 cases and in all groups assessed. In addition, in the six cases when initial escorts were replaced only subgroups were involved (two pairs, three trios and one quad). Given the fusion-fission nature of humpback whale social organization, when not engaged in competition males are found singing alone, performing guarding behavior with a female, or forming pairs/trios with other males, in a sort of fluid associations lasting from a few hours to several days (Baker \& Herman, 1984; Brown \& Corkeron, 1995; Clapham et al., 1992; Darling, Gibson, \& Silber, 1983; Darling et al., 2006; Felix \& Haase, 2001; Mobey \& Herman, 1985; Valsecchi, Hale, Corkeron, \& Amos, 2002). Despite its short duration, it seems reasonable to assume that these temporary associations are the basis of competitive groups and provide the framework for cooperation as well. Cooperation between humpback whales in a fluid basis appears to be common also when foraging at feeding grounds (Clapham, 1993; Weinrich \& Kuhlenberg, 1991). Considering that during the breeding season adult whales must prioritize sexual interactions, male-male cooperation could be a way to increase mating chances by lower ranking animals when competing with other males for access to a female as occurs in some primate species (e.g., Bercovitch, 1988; Watts, 1998). It has been demonstrated that male chimpanzees who engaged in mate-guarding coalitions achieve higher mating success than they would by mate guarding alone (Watts, 1998). Competition and cooperation are interrelated in humpback whale competitive groups as occurs with other mammals and distant taxa such as birds and insects to obtain immediate or deferred fitness benefits (Muller \& Mitani, 2005). In the case of humpback whales, the ability to adapt to dynamic circumstances and making concessions to cooperate under pressure with other males would be an adaptive strategy to either displace dominant escorts or to fend off other challengers.

In half of Ecuadorian competitive groups one animal stayed with the nuclear animal until the end of the observation period, maintaining a privileged position over other males that associated temporally with the group. It is possible that strong males can deter alone the harassment from challengers, and may well be referred to as the principal escort (sensu Baker \& Herman, 1984; Tyack \& Whitehead, 1983). However, we were unable to define such a dominant role in the field in terms of a specific position with respect to the nuclear animal or by its aggressive attitudes towards other whales. Instead, we were only able to do so after the photographic analysis and quantification of their association index. This is why we prefer not to refer those males as a principal escorts but as dominant animals. An alternative explanation is that these animals accepted the presence of other challengers and created opportunistic cooperative units instead of fighting to stay within the group. We regularly observed escorts flanking the nuclear animal from different sides, sometimes in the front of the group cutting the path of the nuclear animal or in the rear, and instead of maintaining a fixed position the escorts seemed to exchange roles. Similar cooperative behavior has been reported by Darling (2006) and Jones (2010) in Hawaii. Cooperation can be developed with little planning and anticipation of the results because animals would learn the benefits of joining forces from previous experiences. We recognize, however, that the poor water visibility in our study area caused by a primary productivity as high as $760 \mathrm{mgC} / \mathrm{m}^{3} / \mathrm{d}$ (Jiménez \& Pesantes, 1978) prevent us to make a more acute focal following of individuals beyond the short surfacing time. Once whales started a dive it was not possible to identify any type of interaction underwater such as who is producing bubbles or charging other animal. It has been demonstrated that competitive groups continue their activity from surface to bottom and may dive down to around $300 \mathrm{~m}$ (Herman et al., 2008).

The presence of two or three females in the same competitive group suggest a more complex level of organization that would favor male cooperation to maximize mating opportunities by bringing several females in one group (Pomilla \& Rosembaum, 2006). It was not clear whether this was a deliberate action by males or produced by random encounters of smaller competitive groups. The arrival of a new subgroup of escorts had a destabilizing effect, triggering displacement, exchange of escorts, rupture or the creation of new coalitions. On three occasions this confusion seemed to favor an escort that "escaped" with the nuclear individual, which supports Clapham et al. (1992) claim that competitive groups finalize when the principal escort stays with the nuclear animal. Our data partially supports this statement, mostly because we have no evidence that those nuclear animals were females. So we cannot rule out the 
displacement of a male dyad by another pair of escorts. In observation Group \#2, which involved a mother and calf pair, the inclusion of a trio caused such instability in the group structure that the female and her calf were able to escape after a first failed attempt. In September 2013 we also saw a mother/calf pair with an escort moving out the bay toward two whales engaged in surface activity. At about $200 \mathrm{~m}$ from the active animals the escort moved forward and the mother and calf returned to the bay without the escort. It is possible that females, especially mothers with calf, see at the arrival of new individuals the opportunity to "get rid" of escorts or "escape" from a competitive group. It has been demonstrated that the energy expenditure by mothers with calves would increase significantly when accompanied by escorts or are part of a competitive group (Cartwright $\&$ Sullivan, 2009) and thus evading escorts seems a necessary measure.

On the other hand, it has been reported that around one third of competitive groups in the Caribbean and Australia contained only males (Brown \& Corkeron, 1995; Clapham et al., 1992). This would mean either that they were residual competitive groups or that competitive groups may be organized also for other purposes, perhaps a type of training in preparation of young males to challenge dominant escorts. Since copulation has not been witnessed in humpback whales, until accurate information on how and when humpback whales mate and what social and behavioral conditions are involved, it will remain open to discussion whether copulation is the aim of competition. Males could employ different mating alternatives other than participating in competitive groups to increase reproductive success such as escorting a mother with a calf waiting for postpartum ovulation (Clapham, 1996).

The intense surface activity recorded in the two observations that were initiated before the formation of competing groups (\#2 and 7) seemed to inform other males about the presence of a mature female, which is consistent with previous descriptions in this area (Félix, 2004). In both observations, however, one of the active animals was displaced by pairs who approached aggressively fast. In Group $\# 2$, one active animal was identified as a subadult. It has been suggested that females aggressively repel young males (Clapham et al., 1992) and this would explain the initial intense surface activity. It seems also possible that physical constraints would prevent young animals to mate with mature female and therefore a competitive group gives youngsters the opportunity to be initiated in the reproductive process, something that also promotes cooperation. Spitz, Herman, Pack, and Deakos (2002) found that a third of participants in competitive groups in Hawaii were immature. In similar way, Jones (2010) reported that young males are more probably to be found chasing females than larger males. Coalitions and alliances by young males have been observed in toothed cetaceans such as bottlenose dolphins that develop strong and lasting bonds early in their lives (Connor, Smolker, \& Richards, 1992; Wells, 1991). By now it seems improbable that such level of organization is present in humpback whales, however, the study of the structure of competitive groups may help to understand the complexity of short-lasting social interactions in this specie as well as the role and the learning process of younger classes during the breeding season.

\section{Acknowledgements}

We thank to Nicky Ransome, Alan Fleming and Juan Carlos Vizuete for their help during the fieldwork. The crew: Jamil Basan, Angel Basan and "Changola". JA thanks Juan Carlos Vizuete for his permanent support. Gustavo Cabrera edited the videos. David Matilla and two anonymous reviewers made valuable comments to improve this article. The Cetacean Society International (CSI) financed partially this research. This study was authorized by the Santa Elena Direction of the Ministry of Environment of Ecuador (Letter No. MAE-DPSE-2010-0580).

\section{References}

Acevedo, J., Rasmussen, K., Félix, F., Castro, C., Llano, M., Secchi, E., ...Pastene, L. (2007). Migratory destinations of the humpback whales from Magellan Strait feeding ground, Chile. Marine Mammal Science, $23,453-463$. 
Bercovitch, B. (1988). Coalitions, cooperation and reproductive tactics among adult male baboons. Animal Behaviour, 36, 1198-1209.

Baker C. S., \& Herman, L. M. (1984). Aggressive behavior between humpback whales (Megaptera novaeangliae) wintering in Hawaiian waters. Canadian Journal of Zoology, 62, 1922-1937.

Brown, M. R., \& Corkeron, P. J. (1995). Group characteristics of migrating humpback whales (Megaptera novaeangliae) migrating off Point Lookout, Queensland. Behaviour, 132, 163-179.

Cartwright, R., \& Sullivan, M. (2009). Associations with multiple male groups increase the energy expenditure of humpback whale (Megaptera novaeangliae) female and calf pairs on the breeding grounds. Behaviour, 145, 1573-1600.

Clapham, P. J. (1993). Social organization of humpback whales on a North Atlantic feeding ground. Symposia of the Zoological Society of London, 66, 131-145.

Clapham, P. J (1996). The social and reproductive biology of humpback whales: An ecological perspective. Mammal Review, 26, 27-49.

Clapham P. J., Palsboll, P. J., Matilla, D. K., \& Vasquez, O. (1992) Composition and dynamics of humpback whale competitive groups in the West Indies. Behaviour, 122, 182-194.

Craig, A. S., Herman, L. M., \& Pack, A. A. (2002). Male mate choice and male-male competition coexist in the humpback whale (Megaptera novaeangliae) Canadian Journal of Zoology, 80, 745-755.

Connor, R. C., Smolker, R. A., \& Richards, A. F. (1992). Dolphin alliances and coalitions. In A. M. Marcourt and F. B. M. de Waal (Eds), Coalitions and alliances in humans and other animals (pp. 415-443). Oxford Science Publications. UK.

Darling, J. D. (2001). Characterization of behavior of humpback whales in Hawaiian waters. Report to Hawaiian Islands Humpback Whale National Marine Sanctuary. Honolulu, Hawaii. USA.

Darling, J. D., Gibson, K. M., \& Silber, G. K. (1983). Observations on the abundance and behavior of humpback whales (Megaptera novaeangliae) off West Maui, Hawaii, 1977-79. In R. Payne (Ed.), Communication and behavior of whales (pp. 201-222). Boulder, CO: Westview Press.

Darling, J. D., Jones, M. E., \& Nicklin, C. P. (2006). Humpback whale songs: Do they organize males during the breeding season? Behaviour, 143, 1051-1101.

Félix, F. (2004). Assessment of the surface activity in humpback whales during the breeding season. Latin American Journal of Aquatic Mammals, 3, 25-36.

Félix, F., \& Botero, N. (2011). Distribution and behaviour of humpback whales mother/calf pairs during the breeding season off Ecuador. Marine Ecology Progress Series, 426, 277-287.

Félix, F., \& Botero, N. (2012). Evaluating humpback whale (Megaptera novaeangliae) social behavior through sexing active individuals. Aquatic Mammals, 38, 301-306. doi: 10.1578/AM.38.3.2012.301

Félix, F., Caballero, S., \& Olavarría, C. (2012). Genetic diversity and population structure of humpback whales (Megaptera novaeangliae) from Ecuador based on mitochondrial DNA analyses. Journal of Cetacean Research and Management, 12, 71-77.

Félix, F., \& Haase, B. (2001). The humpback whale off the coast of Ecuador, population parameters and behavior. Revista de Biología Marina y Oceanografía, 36, 61-74.

Félix, F., Muñoz, M., Falconí, J., Botero, N., \& Haase, B. (2011). Entanglement of humpback whales in artisanal fishing gear in Ecuador. Journal of Cetacean Research and Management, Special Issue 3, 285-290.

Florez-González, L., Ávila, I. C., Capella, J. C., Falk, P., Félix, F., Gibbons, J., ...Van Waerebeek, K. (2007). Estrategia para la Conservación de la Ballena Jorobada del Pacífico Sudeste. Lineamientos para un plan de acción regional e iniciativas nacionales. Cali, Colombia. Fundación Yubarta.

Gilson, A., Sylvanen, M., Levine, K., \& Banks, J. (1998). Deer gender determination by polymerase chain reaction: Validation study and application to tissues, bloodstains and hair forensic samples from California. California Fish and Game, 84, 159-169.

Herman, E. Y. K., Herman, L. M., Pack, A. A., Marshal, G., Shepard, C. M., \& Makhtiari, M. (2008). When whales collide: Crittercam offers insight into the competitive behavior of humpback whales on their Hawaiian wintering grounds. Marine Technology Society Journal, 41, 35-43.

International Whaling Commission. (1998). Report of the Scientific Committee. Reports International Whaling Commission, 48, 53-118.

Jiménez, R., \& Pesantes, F. (1978). Fitoplancton, producción primaria y pigmentos en aguas costeras ecuatorianas. Publicación Instituto Oceanográfico de la Armada del Ecuador (INOCAR), 2, 1-30.

Jones, M. (2010). Female humpback whale (Megaptera novaeangliae) reproductive class and male-female interactions during the breeding season (unpublished $\mathrm{PhD}$ dissertation). Antioch University New England, Keene, N. H. 
Mobley J. R., \& Herman, L. M. (1985). Transience of social affiliations among humpback whales (Megaptera novaeangliae) on the Hawaiian wintering grounds. Canadian Journal of Zoology, 63, 762-772.

Muller, M. N., \& Mitani, J. C. (2005). Conflict and cooperation in wild chimpanzees. Advances in the Study of Behavior, 35, 275-331.

Olavarría, C., Baker, C. S., Garrigue, C., Poole, M., Hauser, N., Caballero, S., ...Russell, K. (2007). Population structure of South Pacific humpback whales and the origin of the eastern Polynesian breeding grounds. Marine Ecology Progress Series, 330, 257-268.

Pacheco, A. S., Silva, S., \& Alcorta, B. (2009). Winter distribution and group composition of humpback whales (Megaptera novaeangliae) off northern Peru. Latin American Journal of Aquatic Mammals, 7, 33-38.

Pack, A. A., Herman, L. M., Spitz, S. S., Hakala, S., Deakos, M. R., \& Herman, E Y. K. (2009). Male humpback whales in the Hawaiian breeding grounds preferentially associate with larger females. Animal Behaviour, $88,653-662$.

Pack, A. A., Herman, L. M., Spitz, S. S., Craig, A. S., Hakala, S., Deakos, M. R., ...Lowe, C. (2012). Sizeassortative pairing and discrimination of potential mates by humpback whales in the Hawaiian breeding grounds. Animal Behaviour, 84, 983-993.

Pomilla, C., \& Rosenbaum, H. C. (2006). Estimates of relatedness in groups of humpback whales (Megaptera novaeangliae) on two wintering grounds of the Southern Hemisphere. Molecular Ecology, 15, 2541-55.

Rasmussen, K., Palacios, D. M., Calambokidis, J., Saborio, M. T., Dalla Rosa, L., Secchi, E. R., ...Stone, G. S. (2007). Southern hemisphere humpback whales wintering off Central America: Insights from water temperature into the longest mammalian migration. Biological Letters, 3, 302-305. doi: 10.1098/rsbl.2007.0067

Spitz, S. S., Herman, L. M., Pack, A. A. \& Deakos, M. H. (2002). The relation of body size of male humpback whales to their social roles on the Hawaiian winter grounds. Canadian Journal of Zoology, 80, 1917-1938.

Tyack, P., \& Whitehead, H. (1983). Male competition in large groups of wintering humpback whales. Behaviour, $83,132-154$.

Valsecchi, E., Hale, P., Corkeron P., \& Amos W. (2002). Social structure in migrating humpback whales (Megaptera novaeangliae). Molecular Ecology, 11, 507-518.

Watts, D. (1998). Coalitionary mate-guarding by male chimpanzees at Ngogo, Kibale National Park, Uganda. Behavioral Ecology and Sociobiology, 44, 43-55.

Wells, R. S. (1991). The role of long-term study in understanding the social structure of a bottlenose dolphin community. In K. Pryor \& K. Norris (Eds), Dolphin societies: Discoveries and puzzles. Berkely, CA: University of California Press.

Weinrich, M. T. (1995). Humpback whales competitive groups observed on high-latitude feeding ground. Marine Mammal Science, 11, 251-254.

Weinrich, M. T. \& Kuhlberg, A. E. (1991). Short-term association patterns of humpback whales (Megaptera novaeangliae) groups on their southern Gulf of Maine feeding grounds. Canadian Journal of Zoology, 69, 3005-3011. 